\title{
Health Information Systems: Between Shared Care and Body Area Networks
}

\section{Findings from the Section on Health Information Systems}

\author{
0. J. Bott, Managing Editor for the IMIA Yearbook Section on Health Information Systems \\ Technical University of Braunschweig, Institute for Medical Informatics, Braunschweig, Germany
}

\section{Introduction}

The field of health information systems (HIS) remains heterogeneous. Research issues include eHealth infrastructures to support transinstitutional health care processes including health record systems [1, 2], integration of knowledge based decision-support systems [3], patient empowerment especially through including patients as HIS users [4], HIS evaluation [5], methods and tools for the analysis, development and management of HIS $[1,6]$, the utilization of new technologies like wearable systems [7] or ubiquitous computing in health, home and personal care [8], the use of HIS data for research and health care management [9], and the utilization of new data types like genomic data to name but a few.

\section{Best Paper Selection}

One objective of the IMIA Yearbook is to review research articles of the last year to identify research trends and excellent research papers in the different fields of medical informatics. Like last years $([8,10])$, the best paper selection for the section 'health information systems' in the IMIA Yearbook 2006 presents examples of excellent research in the field of heath information systems. Five papers were selected from five international peer reviewed journals in the fields of medicine and medical informatics, representing research from four different nations. Table 1 presents the selected articles. A brief content summary of the selected papers can be found in the appendix of this report.

\section{Conclusions and Outlook}

An important topic of HIS research remains the support of shared care through introducing suitable information technology infrastructures including electronic health record systems (EHR). Interoperability and lack of accepted standards are ongoing problems, but as demonstrated in [11] solutions based on standards are feasible and can convey patient empowerment through giving the patient access to HIS data via an EHR system. Medical and technical progress e.g. in biomedicine produces new data types needed to be incorporated in EHR and used for research. The work of [12] concerning genomic data demonstrates that standard techniques of ensuring data privacy may be insufficient and concludes that each new data type processed and transferred in HIS requires a thorough analysis of implications for data safety and security. Home care and home monitoring are also attracting ongoing interest of the research community. In addition to the telemedical surveillance of chronically ill patients using sophisticated, un- 
Table 1: Best paper selection of articlesfor the IMIA Yearbook of Medical Informatics 2006 in the section 'health information systems'. The articles are listed in al phabetical order of the first author's surname.

\section{Section}

Health Information Systems

- Anliker U, Ward JA, Lukowicz P, Tröster G, Dolveck F, Baer M, et al. AMON: a wearable multiparameter medical monitoring and alert system. IEEE Trans Inf Technol Biomed. 2004 Dec; 8(4): 415-27.

- Lenz R, Buessecker F, Herlofsen H, Hinrichs F, Zeiler T, Kuhn KA. Demand-driven evolution of IT systems in healthcare-a case study for improving interdisciplinary processes. Methods Inf Med. 2005; 44(1): 4-10.

- Malin B, Sweeney L. How (not) to protect genomic data privacy in a distributed network: using trail re-identification to evaluate and design anonymity protection systems. I Biomed Inform. 2004 Jun; 37(3):179-92.

- Müller ML, Ückert F, Bürkle T, Prokosch HU. Cross-institutional data exchange using the clinical document architecture (CDA). Int J Med Inform. 2005 Mar; 74(2-4): 245-56.

- Stefanov DH, Bien Z, Bang WC. The smart house for older persons and persons with physical disabilities: structure, technology arrangements, and perspectives. IEEE Trans Neural Syst Rehabil Eng. 2004 Jun; 12(2): 228-50.

obtrusive wearable monitoring devices as demonstrated by [13], technology driven home care concepts for the elderly and physically disabled remains an important field of research [14]. Thus HIS are subject to continuous change indicating a need for systematic and efficient tool-supported methods for change management [1]. A responsive IT infrastructure together with the combination of modern change management and software engineering methods may be key success factors for HIS management [15]. Besides successful research concerning important aspects of HIS, achieving interoperability and integration of health information subsystems and technology remains an important field of work.

Up-to-date information about current and future issues of the IMIA Yearbook is available at http://iig.umit.at/yearbook/.

\section{Acknowledgement}

We greatly acknowledge the support of Martina Hutter and of the reviewers in the selection process of the IMIA yearbook

\section{References}

1. Haux R. Health information systems - past, present, future. Int J Med Inform 2006 Mar-Apr; 75(3-4): 268-81.

2. Giuse DA, Kuhn KA. Health information systems challenges: the Heidelberg conference and the future. Int J Med Inform,2003; 69(2-3): 105-14.

3. Bates DW, Kuperman GJ, Wang S, Gandhi T, Kittler A, Volk L, et al. Ten commandments for effective clinical decision support: making the practice of evidence-based medicine a reality. J Am Med Inform Assoc 2003; 10(6): 523-30.

4. Ross SE, Lin CT. The effects of promoting patient access to medical records: a review. J Am Med Inform Assoc 2003; 10(2): 129-38.

5. Kaplan B, Shaw NT, Future directions in evaluation research: people, organizational, and social issues. Methods Inf Med 2004; 43(3): 215-31.

6. Winter A, Brigl B, Wendt T. Modeling hospital information systems. Part 1: The revised threelayer graph-based meta model 3LGM2. Methods Inf Med 2003; 42(5): 544-51.

7. Lukowicz P, Kirstein T, Troster G. Wearable systems for health care applications. Methods Inf Med 2004; 43(3): 232-8.

8. Bott OJ, Ammenwerth E, Brigl B, Knaup P, Lang E, Pilgram R, Pfeifer B, et al. The challenge of ubiquitous computing in health care: technology, concepts and solutions. Findings from the IMIA Yearbook of Medical Informatics 2005. Methods Inf Med 2005; 44(3): 473-9.

9. Maojo V, Martin-Sanchez F. Bioinformatics: towards new directions for public health. Methods Inf Med 2004; 43(3): 208-14.

10. Knaup P, Ammenwerth E, Brandner R, Brigl B, Fischer G, Garde $S$, et al. Towards clinical bioinformatics: advancing genomic medicine with informatics methods and tools. Methods Inf Med 2004; 43(3): 302-7.

11. Muller ML, Uckert F, Burkle T, Prokosch HU. Cross-institutional data exchange using the clinical document architecture (CDA). Int J Med Inform 2005; 74(2-4): 245-56.

12. Malin B, Sweeney L. How (not) to protect genomic data privacy in a distributed network: using trail reidentification to evaluate and design anonymity protection systems. J Biomed Inform 2004; 37(3): 179-92.

13. Anliker, U., et al., AMON: a wearable multiparameter medical monitoring and alert system. IEEE Trans Inf Technol Biomed, 2004. 8(4): p. 415-27.

14. Stefanov DH, Bien Z, Bang WC, The smart house for older persons and persons with physical disabilities: structure, technology arrangements, and perspectives. IEEE Trans Neural Syst Rehabil Eng 2004; 12(2): 228-50.

15. Lenz R, Buessecker F, Herlofsen H, Hinrichs F, Zeiler T, Kuhn KA. Demand-driven evolution of IT systems in healthcare - a case study for improving interdisciplinary processes. Methods Inf Med 2005; 44(1): 4-10.

16. Lorenzi NM, Riley, RT. Organizational issues = change. Int J Med Inform 2003; 69(2-3): 197-203.

17. CEN/ISS e-Health Standardization Focus Group. Current and future standardization issues in the eHealth domain: Achieving interoperability. http:// www.centc251.org/ehealthfocusgroup.htm; 04.03.2005 (last access Jan. 30, 2006).

18. Dolin RH, Alschuler L, Boyer S, Beebe C, Behlen FM, Biron PV, et al. HL7 Clinical Document Architecture, Release 2. J Am Med Inform Assoc 2006; 13(1): 30-9.

19. Haux R, Ammenwerth E, Herzog W, Knaup P.Health care in the information society. A prognosis for the year 2013. Int J Med Inform 2002; 66(1-3): 3-21.

20. Roback K, Herzog A. Home informatics in healthcare: assessment guidelines to keep up quality of care and avoid adverse effects. Technol Health Care 2003; 11(3): 195-206.

Correspondence to:

Dr.-Ing. Oliver J. Bott

Technical University of Braunschweig

Institute for Medical Informatics

Muehlenpfordtstrasse 23

38106 Braunschweig

Germany

E-mail: o.bott@ mi,tu-bs,de 


\section{Appendix: Content Summa- ries of Selected Best Papers, Section Health Information Systems}

\author{
Anliker U, Ward JA, Lukowicz P, Tröster G, \\ Dolveck F, Baer M, Keita F, Schenker EB, \\ Catarsi F, Coluccini L, Belardinelli A, \\ Shklarski D, Alon M, Hirt E, Schmid R, \\ Vuskovic M.
}

AMON: a wearable multiparameter medical monitoring and alert system.

\section{IEEE Trans Inf Technol Biomed. 2004 Dec;8(4):415-27}

The paper of Urs Anliker et al. presents results of a research project aiming at the development of a wearable medical monitoring and alert system for the surveillance of high-risk cardiac respiratory patients [13]. The wristworn multi sensor system called AMON combines multiparameter monitoring $\left(\mathrm{SpO}_{2}, \mathrm{ECG}\right.$, blood pressure), activity monitoring through a two-axis acceleration sensor, online-analysis and emergency recognition with a flexible communication interface (GSM/GPRS, SMS). The concept includes a telemedicine center where medical staff is enabled to remotely monitor the AMON device, to get in contact with the patient, and to have access to the patient's record, patient diagnostic processing, exception condition processing, and reporting. The system has been validated by a medical study through monitoring 33 volunteers. User perception and wearability were evaluated using a questionnaire indicating that the device gives the subjects a feeling of security allowing them to participate in

\footnotetext{
* The complete papers can be accessed in the Yearbook's full electronic version, provided that permission has been granted by the copyright holder(s)
}

normal life, and that confidentiality of the transmitted data seems to be no issue when deciding about using the system. Even if the device does not fulfill all of the expectations concerning the accuracy on the measurements the system gives impressive insights into the design and telemedical embedding of wearable systems for home care scenarios.

\section{Lenz R, Buessecker F, Herlofsen H, Hinrichs} F, Zeiler T, Kuhn KA.

Demand-driven evolution of IT systems in healthcare — a case study for improving interdisciplinary processes.

\section{Methods Inf Med. 2005; 44(1): 4-10}

Health care processes are subject to continuous change inducing new requirements on information processing and a corresponding adaptation of health information systems. Thus HIS management is closely related to change management [16]. Methods and tools are needed to manage this change process efficiently and systematically. The paper of Richard Lenz et al. [15] presents an IT-supported model for demand-driven evolution of HIS useful for analyzing and optimizing interdisciplinary clinical processes. It comprises modeling of the target process, failure analysis, simulation based evaluation of the target process model and implementation of the identified applications and information flows using a computer-aided software engineering tool. The approach has been applied and evaluated in a project concerning the optimization of preoperative autologous blood donation. The evaluation reveals remarkable process improvements concerning the process duration, and the processing and waiting times. The results demonstrate that HIs management profits from the combination of modern methods of change management and software engineering. The prerequisite for applying this approach is an HIS IT infrastructure that supports efficiently continuous adaptation.

\section{Malin B, Sweeney L.}

How (not) to protect genomic data privacy in a distributed network: using trail reidentification to evaluate and design anonymity protection systems.

\section{J Biomed Inform. 2004 Jun;37(3):179-92}

Biomedicine and bioinformatics have made enormous progress the last years. Genomic data has proven useful for discovering the causes of diseases and to find new diagnostic and therapeutic methods [9]. Besides these great opportunities, questions arise concerning genomic data safety and security. The paper of Bradley Malin and Latanya Sweeney [12] addresses the issue of preserving privacy when enabling access to genomic data in distributed networks. The authors introduced several algorithms that re-identify patients by linking genomic information with publicly available patient data, and applied these algorithms to real-world data. The results impressively demonstrate that standard techniques of anonymization and pseudonymization may not be sufficient to preserve privacy when processing and transferring genomic data. The paper concludes that formal methods are needed to systematically test privacy protection methods against current re-identification techniques.

Müller ML, Ückert F, Bürkle T, Prokosch HU. Cross-institutional data exchange using the clinical document architecture (CDA).

\section{Int J Med Inform. 2005 Mar;74(2-4):245-56}

Worldwide initiatives are underway to establish information technology infrastructures aiming at efficiently supporting shared care. Standards are essential 
to achieve the required level of interoperability [17]. The Clinical Document Architecture (CDA) of HL7 [18] is a prominent candidate for the international standardization of electronic document exchange in health care. The paper of Marcel Lucas Müller et al. [11] presents experiences with using the CDA for the electronic transfer of discharge letters from a hospital to general practitioners and for the integration of clinical data such as discharge and referral letters or laboratory results in a patient's lifelong electronic health record. Both the discharge letter exchange and the EHR integration of clinical documents have been introduced into clinical routine and were evaluated. The email based discharge letter exchange is encouraging, but currently facing problems concerning its embedding into clinical routine and the integration of the documents into the GP's practice software. The EHR integration is well appreciated by patients and impressively supports the assumption that access to timely medical information us- ing an internet based EHR system is an important and demanded mean of patient empowerment. The authors come to the conclusion that HL7 CDA is a useful and flexible approach to support exchange of clinical data among health care professionals.

\section{Stefanov DH, Bien Z, Bang WC.}

The smart house for older persons and persons with physical disabilities: structure, technology arrangements, and perspectives.

\section{IEEE Trans Neural Syst Rehabil Eng. 2004 Jun; 12(2):228-50}

The demographic development especially in western countries moves towards an increasing number of elderly people inducing a growing demand for health care services [19]. Limited resources of health care systems enforce the search for alternatives to expensive care in hospitals or ambulatory settings. Also elderly people and people with physical disabilities are interested in residing as long as possible in their per- sonal environment. Home care enabled or supported by technology is one concept to meet these requirements [20]. The paper of Ditimar H. Stefanov et al. [14] presents a comprehensive review of current research on so called smart houses and technologies they may be equipped with. Based on a classification of smart home devices into the five groups (1) devices for automation and control of the home environment, (2) assistive devices, (3) devices for health monitoring of important vital parameters, (4) devices for information exchange, and (5) leisure devices, the authors comment in detail on research and development outcome. The review is complemented by a proposal for a functional architecture of an "Intelligent Robotic House" pointing out future research issues. The authors conclude that research outcomes concerning smart houses for the elderly and disabled may also be transferred to healthy people, helping to prevent diseases and therefore prolong life expectancy in the near future. 